\title{
Management of a Complication of Percutaneous Gastrostomy in Children
}

\author{
Rashmi Roshan Singh ${ }^{1}$ Simon Eaton ${ }^{2}$ Kate M. Cross ${ }^{3}$ Joe I. Curry ${ }^{3}$ Paolo De Coppi ${ }^{1,3}$ \\ Edward M. Kiely ${ }^{3}$ Derek J. Roebuck ${ }^{4}$ Agostino Pierro ${ }^{1,3}$
}

${ }^{1}$ Department of Surgery, Institute of Child Health, London, United Kingdom

${ }^{2}$ Department of Surgery, UCL Institute of Child Health, London, United Kingdom

${ }^{3}$ Department of Surgery, Great Ormond Street Hospital for Children, London, United Kingdom

${ }^{4}$ Department of Radiology, Great Ormond Street Hospital for Children, London, United Kingdom

Eur J Pediatr Surg 2013;23:76-79.
Address for correspondence and reprint requests Rashmi Roshan Singh, MBBS, MRCS, Department of Surgery, Institute of Child Health, 30 Guilford Street, London WC1N 1EH, United Kingdom (e-mail: rashmi.singh@ucl.ac.uk; rashmi.roshan@yahoo.co.uk).

\begin{abstract}
Keywords

- buried gastrostomy

- bumper

- percutaneous gastrostomy

- children

Aim "Buried bumper" is a complication of percutaneous gastrostomy related to the internal flange getting buried into the wall of the stomach. The aim of this study is to evaluate the management of this complication.

Methods The surgical and interventional radiology database in our hospital from August 1999 to May 2011 was analyzed. There were 2,007 patients who underwent percutaneous gastrostomy insertion. Notes for patients with buried bumper were reviewed. A telephonic interview with the parents of these children was performed with focused assessment of the care of the gastrostomy tube before the episode of buried bumper. Continuous data are reported as median (range).

Results Twenty children developed buried bumper after gastrostomy insertion. They had a primary diagnosis of neurological $(n=14)$, metabolic $(n=3)$, or endocrine $(n=3)$ disorders. The age at presentation was 5.7 years (2 to 18 years); 2.5 years ( 1 month to 5 years) after gastrostomy insertion. Ten children (50\%) presented with symptoms related to buried bumper which included leakage around the gastrostomy $(n=4)$, pus, discharge or bleeding from the site $(n=5)$, stiffness on feeding $(n=3)$, and unable to push the flange $(n=1)$ (three children had more than one symptom). Ten children (50\%) were asymptomatic and underwent routine change or removal of gastrostomy. In nine children, there was an attempt to remove the flange by interventional radiology but this was successful only in one. In the remaining 19 children, 4 had endoscopic removal while 15 children developed an inflammatory mass and required a laparotomy $(n=12)$ or laparoscopic-assisted excision $(n=3)$.

Conclusion Buried bumper is a rare complication of percutaneous gastrostomy. Inadequate postoperative care without appropriate mobilization is a factor leading to this preventable complication. Endoscopic removal is possible, failing which laparoscopic surgery should be considered.
\end{abstract}

(c) 2013 Georg Thieme Verlag KG Stuttgart · New York
DOI http://dx.doi.org/ 10.1055/s-0032-1330844. ISSN 0939-7248. 


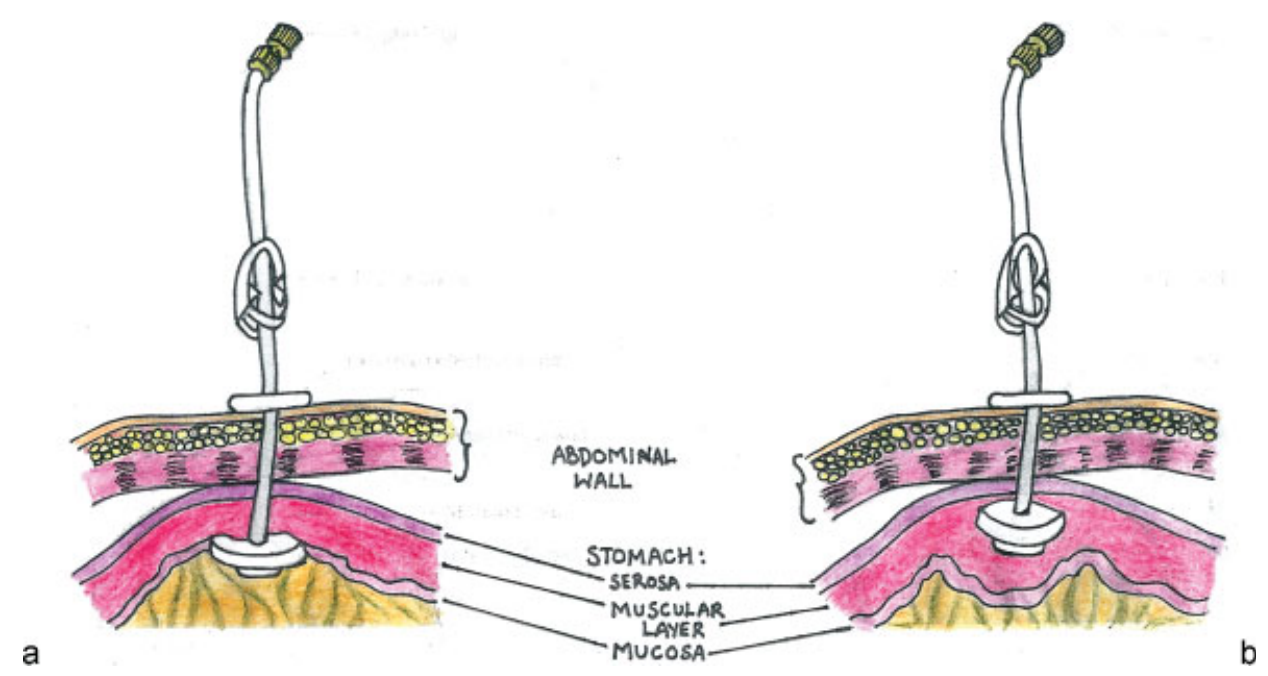

Fig. 1 (a) Correct position of a percutaneous gastrostomy. (b) Buried bumper.

\section{Introduction}

Ever since Gauderer et al described percutaneous endoscopic gastrostomy in 1980, it has become one of the commonest procedures in infants and children. ${ }^{1}$ It is usually performed in infants and children requiring short- to long-term enteral feeding. The common indications for gastrostomy are to provide enteral nutrition and medication for children who have neurological impairment, metabolic disorders, oncological diagnoses, and gastrointestinal disorders. ${ }^{2,3}$

Buried bumper is a rare complication, when the internal bumper or flange of the gastrostomy migrates into the stomach or abdominal wall (-Fig. 1). The gastric mucosa covers the internal surface of the flange of the gastrostomy tube, therefore, giving rise to symptoms such as resistance upon infusing feeds, pain, and peritubular leakage. The incidence has been reported to be 1.3 to $21.8 \%$ in the pediatric population. $^{3-8}$ We present our experience with buried bumpers and their management over the past 12 years.

\section{Patients and Methods}

We obtained institutional ethical approval (No. 10SG14). The surgical and interventional radiology database from August 1999 to May 2011 was analyzed. The records for children with buried bumper were reviewed. We collected the demographic information, clinical diagnosis, symptoms at presentation, age at time of procedure, date of procedure, operative details, early and delayed complications, and length of followup. The percutaneous gastrostomy inserted in all cases was a 9-French Freka gastrostomy tube (Cheshire, UK). A telephonic interview with the parents of these children was performed with focused assessment of the care of the gastrostomy tube before the episode of buried bumper.

\section{Results}

There were 2,007 patients who underwent percutaneous gastrostomy insertion. Twenty children (11 boys) were found to have a buried gastrostomy. Most of them $(n=14)$ had underlying neurological condition. Three had metabolic disorder and three had endocrine disorder.

The age at presentation was 5.75 years ( 2.83 to 18 years). They presented 2.5 years ( 1 month to 5 years) after gastrostomy insertion (-Table 1 ). Half of the children $(n=10)$ presented with symptoms related to buried bumper which included leakage around the gastrostomy $(n=4)$, pus, discharge or bleeding from the site $(n=5)$, stiffness on feeding $(n=3)$, and unable to push the flange $(n=1)$. There were three children with more than one symptom. The other half $(n=10)$ were asymptomatic and were booked for routine change or removal of gastrostomy. In nine children, there was an attempt to remove the flange by interventional radiology but this was successful only in one. A snare was inserted through the catheter hole, under fluoroscopic guidance and the bumper was removed through the esophagus. $^{9}$ In the remaining 19 children, 4 had endoscopic removal while 15 children developed an inflammatory mass and required a laparotomy $(n=12)$ or laparoscopicassisted excision $(n=3)$ (-Fig. 2). The four endoscopic removals included two removed by external traction against the abdominal wall. In the remaining two, the flange was removed by pushing it from the wall of the stomach toward the lumen. To facilitate this, a metal probe was inserted into the shortened gastrostomy tube from outside, stiffening it and allowing the flange to be pushed into the gastric lumen. This was then retrieved by a snare, thus avoiding an open procedure.

The patients were followed up for 12 months (1 to 45 months). There were two complications (10\%). One had a gastrostomy site infection and another an abscess of the old gastrostomy site, each needing oral antibiotics.

\section{Discussion}

Buried bumper has been described in the adult literature to potentially cause perforation of the stomach, peritonitis, and 
78 Management of a Complication of Percutaneous Gastrostomy in Children Singh et al.

Table 1 Patient's age, time since gastrostomy, and method of removal

\begin{tabular}{|l|l|l|l|}
\hline Patient number & Age at presentation (years) & Time since gastrostomy (years) & Removal by \\
\hline 1 & 7 & 5 & Interventional radiology \\
\hline 2 & 3 & 2 & Laparoscopic \\
\hline 3 & 4.5 & 0.58 & Laparotomy \\
\hline 4 & 9.25 & 0.5 & Laparotomy \\
\hline 5 & 3.75 & 2.5 & Laparoscopic \\
\hline 6 & 4.75 & 3.42 & Laparoscopic \\
\hline 7 & 15.2 & 2.5 & Endoscopic \\
\hline 8 & 5.25 & 3.92 & Laparotomy \\
\hline 9 & 12 & 2.1 & Laparotomy \\
\hline 10 & 4.75 & 3.5 & Endoscopic \\
\hline 11 & 12 & 3.25 & Endoscopic \\
\hline 12 & 18 & 3 & Laparotomy \\
\hline 13 & 5.83 & 2.83 & Laparotomy \\
\hline 14 & 2.83 & 1 & Endoscopic \\
\hline 15 & 9.25 & 1.25 & Laparotomy \\
\hline 16 & 4 & 1.42 & Laparotomy \\
\hline 17 & 3.25 & 0.75 & Laparotomy \\
\hline 18 & 7 & 3 & Laparotomy \\
\hline 19 & 12.34 & 0.08 & Laparotomy \\
\hline 20 & 5.6 & 3.84 & Laparotomy \\
\hline
\end{tabular}

death. ${ }^{10}$ The commoner presenting symptoms of difficulty in infusing feeds, pain, and peritubular leak might not be picked up initially, especially in the child with difficult communication.

The diagnosis can be made by the history and occasional palpation of the gastrostomy flange below the skin, with or without pain. ${ }^{11}$ However, in our series palpation did not reveal the buried bumper, which was retained in the stomach wall. Radiological investigations such as ultrasound or computed tomography can be useful. ${ }^{7,11}$ However, the confirmation is made by endoscopy, which shows a mound of gastric mucosa, with minimal or absent visible gastrostomy disk.

Factors implicated in the development of buried bumper are excessive tension between the inner and outer flange of

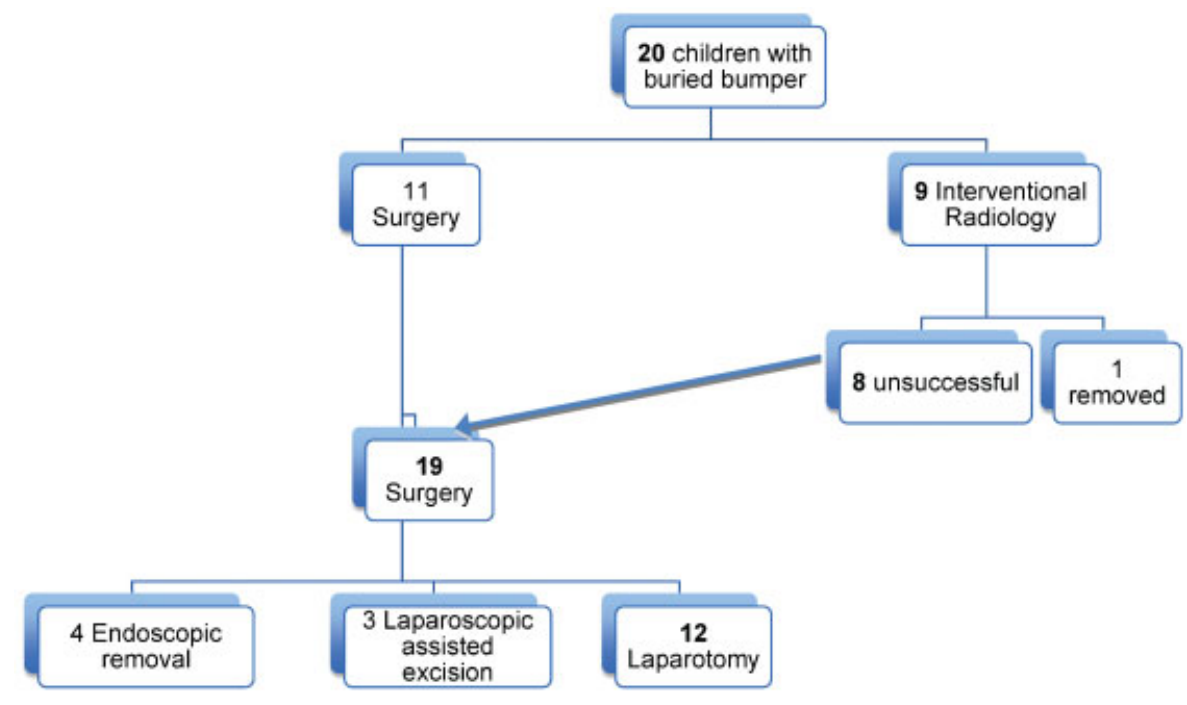

Fig. 2 Management of buried bumpers. 
the gastrostomy, causing pressure necrosis of the gastric mucosa, leading to its migration into the abdominal wall and inadequate gastrostomy care. ${ }^{7,11}$ In a telephonic interview, 15 (75\%) parents/carers were not pushing the gastrostomy tube and rotating it, as is our present recommendation. Four parents could not be contacted and unfortunately, one child had died due to advanced primary disease. The NICE guideline (National Institute for Health and Clinical Excellence) for gastrostomy care in adults recommends weekly tube rotation to prevent internal overgranulation or buried bumper syndrome. ${ }^{12}$ In children, the rotation of the tube should be associated with advancement of the flange weekly to avoid migration of the bumper into the wall of the stomach.

Various approaches have been suggested for the removal of the buried bumper. These include external traction, endoscopic, laparotomy, radiological-guided, and laparoscopic excision. ${ }^{4-9,11,13}$ Our experience in an uncomplicated buried bumper, that is, without an inflammatory mass favors endoscopic-guided removal. In children with an inflammatory mass, laparoscopic-assisted excision facilitates dissection, minimizes tissue disruption, and should be the first choice. Radiological-guided removal of a buried gastrostomy in children is rarely successful and requires an experienced interventional radiologist.

\section{Conclusion}

Buried bumper is an uncommon, serious complication of one of the commonest procedures in children. This can be avoided by proper gastrostomy care. Endoscopic removal should be the first line of treatment, failing which a laparoscopicassisted excision or laparotomy is recommended.

Conflict of Interest

None

\section{References}

1 Gauderer MW, Ponsky JL, Izant RJ Jr. Gastrostomy without laparotomy: a percutaneous endoscopic technique. J Pediatr Surg 1980;15(6):872-875

2 Nah SA, Narayanaswamy B, Eaton S, et al. Gastrostomy insertion in children: percutaneous endoscopic or percutaneous image-guided? J Pediatr Surg 2010;45(6):1153-1158

3 Sathesh-Kumar T, Rollins H, Cheslyn-Curtis S. General paediatric surgical provision of percutaneous endoscopic gastrostomy in a district general hospital-a 12-year experience. Ann R Coll Surg Engl 2009;91(5):404-409

4 Furlano RI, Sidler M, Haack H. The push-pull T technique: an easy and safe procedure in children with the buried bumper syndrome. Nutr Clin Pract 2008;23(6):655-657

5 Köhler H, Lang T, Behrens R. Buried bumper syndrome after percutaneous endoscopic gastrostomy in children and adolescents. Endoscopy 2008;40(Suppl 2):E85-E86

6 Binnebösel M, Klink CD, Otto J, Schumpelick V, Truong S. A safe and simple method for removal and replacement of a percutaneous endoscopic gastrostomy tube after "buried bumper syndrome". Endoscopy 2010;42(Suppl 2):E17-E18

7 Hodges EG, Morano JU, Nowicki MJ. The buried bumper syndrome complicating percutaneous endoscopic gastrostomy in children. J Pediatr Gastroenterol Nutr 2001;33(3):326-328

8 Ségal D, Michaud L, Guimber D, Ganga-Zandzou PS, Turck D, Gottrand F. Late-onset complications of percutaneous endoscopic gastrostomy in children. J Pediatr Gastroenterol Nutr 2001;33(4):495-500

9 Turner P, Deakin M. Percutaneous endoscopic gastrostomy tube removal and replacement after "buried bumper syndrome": the simple way. Surg Endosc 2009;23(8):1914-1917

10 Anagnostopoulos GK, Kostopoulos P, Arvanitidis DM. Buried bumper syndrome with a fatal outcome, presenting early as gastrointestinal bleeding after percutaneous endoscopic gastrostomy placement. J Postgrad Med 2003;49(4):325-327

11 Khalil Q Kibria R, Akram S. Acute buried bumper syndrome. South Med J 2010;103(12):1256-1258

12 National Institute for Health and Clinical ExcellenceCG32 Nutrition support in adults: Oral nutrition support, enteral tube feeding and parenteral nutrition. NICE guideline: NHS; February 2006; 22

13 Ehsan S, Dyall L, Ubhi S. A novel laparoscopic approach for the surgical management of buried bumper syndrome. Ann R Coll Surg Engl 2012;94(1):61-62 